Pak. j. sci. ind. res. Ser. B: biol. sci. 2014 57(3) 148-154

\title{
Isolation and Characterisation of Chitin and Chitosan from Local Sources
}

\author{
Tayyaba Aftab ${ }^{\mathrm{a}}$, Asad ullah ${ }^{\mathrm{b}}$, Muhammad Khalid Iqbal ${ }^{\mathrm{a} *}$, Rauf Ahmed Khan ${ }^{\mathrm{a}}$ and \\ Muhammad Nawaz Chaudhry ${ }^{\mathrm{b}}$ \\ ${ }^{a}$ CEPS, PCSIR Laboratories Complex, Lahore-54600, Pakistan \\ ${ }^{b}$ College of Earth and Environmental Sciences, University of the Punjab, Lahore, Pakistan
}

(received December 9, 2013; revised April 10, 2014; accepted April 15, 2014)

\begin{abstract}
In this study, indigenous shrimp (Gadus morhua) and blue crab (Portunus pelagius, male \& female) from Karachi coastal area were collected. The flesh was extracted to use for eating and the discarded waste was converted to an environment-friendly value-added product chitosan in chemical process after minor modification of DMCPA protocol. Four chitosan samples of shrimp head shells, blue crab leg shells, claw shells and carapace were obtained. The physicochemical and functional properties i.e., colour, degree of deacetylation, moisture, ash contents, nitrogen, viscosity, water and fat binding capacities were evaluated. Comparative study showed good percentage yields of chitosan from crab leg and shrimp head shells as $25.67 \%$ and $22.06 \%$, respectively. Moisture, ash and nitrogen contents were in acceptable ranges. The colour of blue crab leg shell was off-white, while other three were light-yellow. Difference in degree of deacetylation (DD) was significant. The DD was $77 \%$ in crab leg shell, $61.6 \%$ shrimp head shells, $25.5 \%$ crab claw shell and $20.4 \%$ for crab carapace chitosan samples. Viscosity values were low (41-116 cPs). Water and fat binding capacity were in range of $494-521 \%$ and $378-428 \%$, respectively.
\end{abstract}

Keywords: chitosan, moisture, blue crab, adsorption, viscosity

\section{Introduction}

The coastline area of Pakistan stretches over $1046 \mathrm{~km}$ from Gwadar bay to Sir Creek, providing a fishing zone of 240,000 square kilometers. Meanwhile, inland fisheries represent great potential especially in waterlogged zones spread over 50 million hectares in streams. The marine fisheries play an important role in Pakistan's economy being multimillion export sector. During the year 2010, Pakistan exported seafood products worth \$300 million, mainly to China and other Far Eastern countries (Parihar, 2011). In view of this, a great interest has been increased for possible utilisation of fisheries by-products and processed left-over as a promising resource for their valuable protein, sugars and mineral contents, instead of an unacceptable hazardous waste problem (Diaz-Visurraga et al., 2010; Kim and Mendis, 2006). In order to tackle this growing environmental issue, an increased focus is being given to isolate valueadded materials like chitin and its useful derivative chitosan from waste (Du et al., 2009; 2008).

Chitosan is one of the biodegradable, nontoxic, environmental friendly and natural polymer extracted from different types of mollusks, insects, marine diatoms,

*Author for correspondence;

E-mail: khalid_khichi2000@yahoo.com algae, fungi, yeasts, shrimps, crabs, and other crustacean species at industrial scale (Kurita, 2006; Tharanathan and Kittur, 2003; Yanga et al., 2000). Insoluble chitin is converted into a soluble derivative, chitosan after chemical treatment (Iqbal et al., 2005).

These natural polymers encompass the intrinsic properties as an effective colour absorbent because commercial polymers and ion exchange resins are of Petroleum based materials, which are not environment-friendly. In recent years, an interest for natural and low cost polymers is increasing day by day as recent investigations have approved an effective role of chitin and chitosan in various fields of biotechnology, chemistry, environmental safety, medicine, food processing, paper, textile production, cosmetics, agriculture and wastewater treatment (Alves and Mano, 2008). Chitosan is used as flocculant, coagulant and antimicrobial due to chelating properties and adsorbs the colour and heavy metals of effluents (Zaku et al., 2011; Zeng et al., 2008).

In order to surmount the complexity connected to wastewater containing dyes, resistant to aerobic digestion is necessary to remove the colour from industrial effluents. The adsorption of dyes by chitosan is an effective and economic method for water decontamination and reuse for irrigation purposes. 
The objectives of the present study was to isolate chitosan from indigenous fishery crustacean waste (shrimp head shell, crab leg shells, crab claw shells, and crab carapace), to compare its physicochemical and functional characteristics.

\section{Materials and Methods}

Raw material collection and sample preparation. Two local crustaceans white jinga shrimp (Gadus morhua) maximum length of $15 \mathrm{~cm}$ and blue swimming crab (Portunus pelagius) $20 \mathrm{~cm}$ long male and $15 \mathrm{~cm}$ female were collected from Arabian Sea, Karachi coastal area and used to extract chitin. The flesh/meat was separated from waste. In case of white shrimps only head shell was taken and for blue crab (male + female) further segregation into shells of legs, claws and carapaces was done to get four different raw materials (Fig. 1a-f) to isolate chitin and chitosan.

These raw materials were scrapped free of loose tissues, washed with tap water, sun dried for two days, ground, sieved to $250 \mu \mathrm{m}$ size and kept separately in air tight plastic bags at room temperature.

Isolation of chitosan. The extraction was carried out by an alkali-acid chemical treatment method including four steps of demineralisation, decolourisation, deproteinisation and deacetylation called DMCPA protocol.

Demineralisation. The sun-dried crustacean shells were treated with $0.7 \mathrm{~N} \mathrm{HCL}, 1: 15(\mathrm{w} / \mathrm{v})$ for $30 \mathrm{~min}$ at room temperature with constant stirring. Filtered through vacuum filtration and placed under tap water for 30 min until the filtrate became neutral. The $\mathrm{pH}$ was noted, then the material was oven dried at $60^{\circ} \mathrm{C}$ and weighed.

Decolourisation. The crustacean shells after demineralisation step were soaked in acetone at ambient temperature for 10 mins, allowed to dry in dark for $2 \mathrm{~h}$. The shells were bleached for $15 \mathrm{mins}$ by $0.315 \%(\mathrm{v} / \mathrm{v})$ sodium hypochlorite $(\mathrm{NaOCl})$ containing $5.25 \%$ available chlorine. A ratio of $1: 10 \mathrm{w} / \mathrm{v}$ was used to accomplish the bleaching process, excessively washed under tap water and oven dried at $60^{\circ} \mathrm{C}$.

Deproteinisation. The decolourised shells after bleaching were treated with $1.2 \mathrm{~N} \mathrm{NaOH}$ solution in ratio of $1: 10(\mathrm{w} / \mathrm{v})$ for $2.5 \mathrm{~h}$ at $70-75^{\circ} \mathrm{C}$ providing constant stirring. Excessively washed under tap water and oven dried at $60^{\circ} \mathrm{C}$ for $4 \mathrm{~h}$.
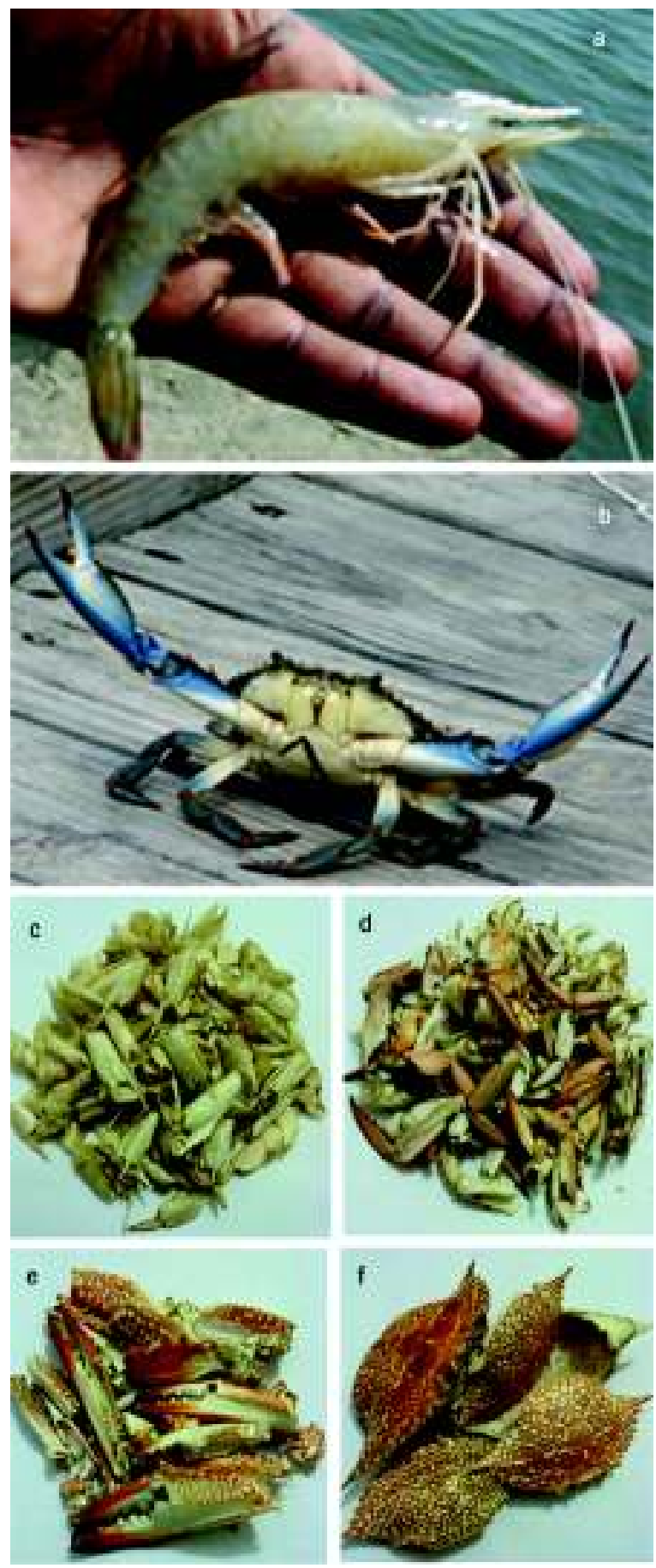

Fig. 1. (a) White jinga shrimp (Gadus morhua); (b) Blue swimming crab (Portunus pelagius); (c) White ginga; (d) Blue crab legs; (e) Blue claws; (f) Blue crab carapace.

Deacetylation of chitin. Chitosan is deacetylated derivative of chitin, so the removal of acetyl group from raw chitin is required. For this purpose raw chitin was 
treated with $50 \% \mathrm{NaOH}$ in ratio $1: 13(\mathrm{w} / \mathrm{v})$ and autoclaved under 15 psi pressure at $121^{\circ} \mathrm{C}$ temperature for $15 \mathrm{~min}$, excessively washed under tap water until neutral. Hot distilled water was used for rinsing of the product, filtration and oven dried at $60^{\circ} \mathrm{C}$ for $24 \mathrm{~h}$.

Analytical analysis. These four isolated samples of chitosan were further characterised for moisture and ash (AOAC, 2005), degree of deacetylation (Kasaai et al., 2000), viscosity (Huang et al., 2011), colour (Tajik et al., 2008), water and fat binding capacity (Wang and Kinsella, 1976). All the analyses were performed in triplicate to assurance the precision and accuracy of the whole experimental work. To investigate the surface characteristics of chitosan, fourier transform infrared (FTIR, Perkin-Elmer spectrophotometer spectrum one) and elemental analysis ( $\mathrm{CHN}$ and $\mathrm{S}$ ) were performed by using the elemental CHNS instruments.

\section{Results and Discussion}

Colour. The colour of isolated chitosan from crab leg shells was off white, while the other three samples were light yellow in colour. Brownish to light yellow colour was observed by Tajik et al. (2008) and whiter to less red by Youn et al. (2007).

Percentage yield of chitosan. The percentage yields of chitin and chitosan was calculated from dry raw shrimp and crab waste. In case of crab claws and carapaces, high percentage weight loss was associated with excessive $\mathrm{CO}_{2}$ gas emission with effervescence and undesirable foam that is a proof of high mineral content loss during demineralisation process (DP).

$$
\mathrm{CaCO}_{3}+2 \mathrm{HCl} \rightarrow \mathrm{CaCl}_{2}+\mathrm{CO}_{2}(\mathrm{~g})+\mathrm{H}_{2} \mathrm{O}
$$

Similarly, after DP process weight loss was highest in shrimp head shells $(47.81-24.91=22.90 \%)$, which indicated high protein content. Highest weight loss (28.26\%) for crab carapaces was due to loss of pigments present on the shell. Demineralisation results are in compliance with Bolat et al. (2010), who found 34.32\% yield out of $60 \%$ dry waste of fresh crab (Potamon potamios), but a final yield of chitosan was quite higher for the white shrimp and blue crab as shown in Fig. 2a.

For shrimp head shells chitosan yield $(22.06 \%)$ was found in equality to that of brine shrimp (23.1\%), mentioned by Tajik et al. (2008), but higher than (15\%), the yield extracted from local Bangladesh shrimp waste mentioned. Yield of chitosan from (25.67\%) crab leg shells, followed by shrimp head shells $(22.06 \%)$, crab carapaces $(13.81 \%)$ and finally crab claws $(11.53 \%)$. Blue crab claw shells exhibited the lowest percentage yield.

It is repeatedly shown in literature that the percentage yield of chitosan in shells waste of different marine species differs extensively, depending on the type of species and the process conditions (Abdou et al., 2008; Chandumpai et al., 2004; Synowiecki and Al-Khateeb, 2003). The raw material with higher amount of crude chitin yield higher chitosan. According to No et al. (2003) difference in the properties of the prepared chitosan depends on the type of marine species and the ways of production.

Moisture content. In all extracted samples the observed moisture was less than $10 \%$ as stated by KFDA in 1995. No significant variation in moisture content of chitosan isolated from shrimp head shell (5.5\%) and crab leg shell (5.6\%), was observed, while some fluctuation in crab claw (6.1\%) and crab carapace (3.9\%), shown in Fig. $2 \mathrm{~b}$ was observed that could be attributed to the hygroscopic nature of chitosan (Ocloo et al., 2011).

Ash content. The ash content of four chitosan samples was in the range of 1.05 to $2.6 \%$. Tajik et al. (2008) have reported that the commercial best grade chitosan contains about $1.18 \%$ ash. Literature is available showing higher values e.g., $4.05 \%$ in local brine shrimp in Bangladesh. Fig. 2c clearly shows that crab leg shell had lowest ash content following by shrimp head shell.

Nitrogen content. Nitrogen contents of four different chitosan samples were shown in Table 1. In 1995, No and Meyers reported a similar range $7.06 \%$ to $7.97 \%$ nitrogen in chitosan samples. Other elemental analysis of chitosan sample showed carbon range $39.59 \%$, $41.78 \%, 45.73 \%, 50.10 \%$, hydrogen range $4.48 \%$,

Table 1. Elemental analysis and colour of four isolated chitosan samples

\begin{tabular}{|c|c|c|c|c|c|}
\hline $\begin{array}{l}\text { Chitosan } \\
\text { source }\end{array}$ & Nitrogen & Carbon & $\begin{array}{l}\text { Hydrogen } \\
(\%)\end{array}$ & $\mathrm{C} / \mathrm{N}$ & Colour \\
\hline $\begin{array}{l}\text { Head shells } \\
\text { (shrimp) }\end{array}$ & 7.20 & 41.78 & 5.10 & 5.78 & Light yellow \\
\hline $\begin{array}{l}\text { Leg shells } \\
\text { (crab) }\end{array}$ & 7.16 & 39.59 & 4.48 & 5.53 & Off white \\
\hline $\begin{array}{l}\text { Claw shells } \\
\text { (crab) }\end{array}$ & 7.15 & 45.73 & 5.13 & 6.39 & Light yellow \\
\hline $\begin{array}{l}\text { Carapaces } \\
\text { (crab) }\end{array}$ & 7.73 & 50.10 & 6.75 & 6.48 & Light yellow \\
\hline
\end{tabular}

Values were rounded off up to two decimal places. 
$5.10 \%, 5.13 \%, 6.75 \%$ and accordingly the $\mathrm{C} / \mathrm{N}$ ratio $5.53,5.78,6.39,6.48$ with a small difference among four extracted samples (Fig. 2d).

Degree of deacetylation. Being an important property of the chitosan samples, the degree of deacetylation value affects other parameters such as biodegradability, chemical reactivity and solubility of chitosan. In the present study, chitosan isolated crab leg shells and shrimp head shell had good degree of deacetylation as $77 \%$ and $61.6 \%$, respectively. The results by claw shell and carapace chitosan were not within the reported values in literature. Degree of deacetylation depends on raw material, the extraction method, sample preparation and experimental conditions (Khan et al., 2002). A range of 30-90 percent degree of deacetylation was reported by Martino et al. (2005).

Viscosity. In the present study the values of viscosities in four isolated chitosan samples were lower ranging from 41 to $116.3 \mathrm{cPs}$ (Table 2). Reduction in viscosity may be due to the use of bleaching agent or after protein extraction (Moorjani et al., 1975). The viscosity range of 26-360 cPs for chitosan is reported by No et al. (2000). Similarly, in another study by Bough et al. (1978) a wider range of viscosity (60 to $5110 \mathrm{cPs}$ ) was reported. It was observed that crab leg and shrimp shell chitosan have higher values of viscosity than carapace and claw shell chitosan. Far lower viscosities of the samples indicate their limited applicability in food, cosmetic and medicine industry because of difficulties in handling, poor suspension and thickening agents (Tajik et al., 2008).

Water and fat binding capacity. The water binding capacity value of four chitosan samples were in the range of $244 \%$ to $521 \%$. It was observed that chitosan obtained from crab leg shells exhibited more capacity to bind water, on the other hand shrimp head shell chitosan with 494\% WBC (water binding capacity) show comparable result to crab leg shells. Whereas, crab claw shells and crab carapace have $244 \%$ and

Table 2. Viscosity of four isolated chitosan samples

\begin{tabular}{ll}
\hline \hline Chitosan source & Viscosity (cPs) \\
\hline Head shells (shrimp) & $97 \pm 1.52$ \\
Crab leg shells & $116 \pm 0.57$ \\
Crab claw shells & $41 \pm 1.15$ \\
Crab carapaces & $54 \pm 1.15$ \\
\hline
\end{tabular}

Mean \pm standard deviation of triplicate determinations.
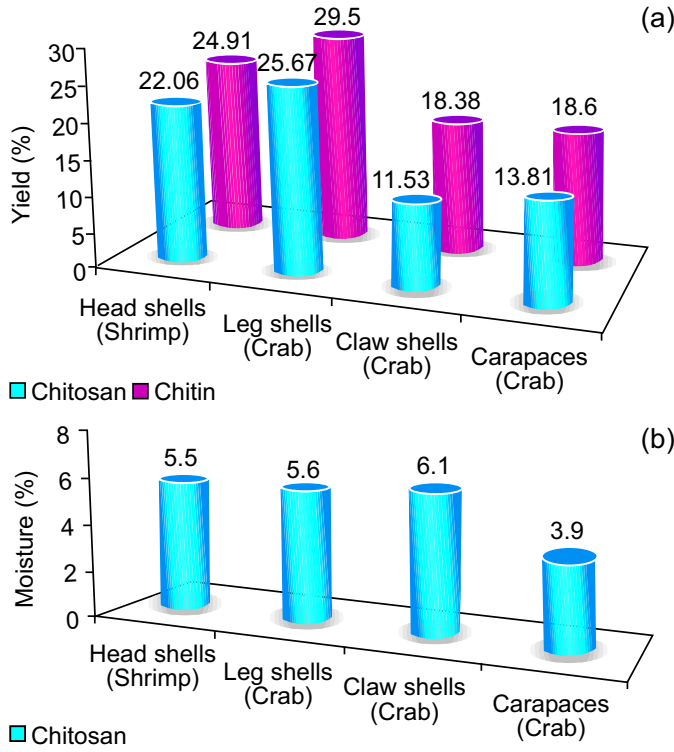

(b)
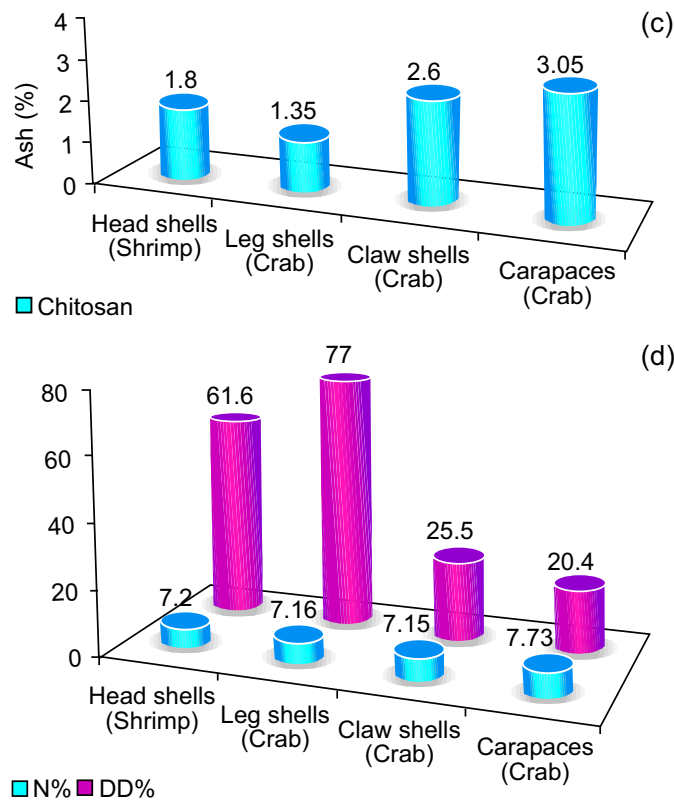

(d)

$\square \mathrm{N} \% \square \mathrm{DD} \%$

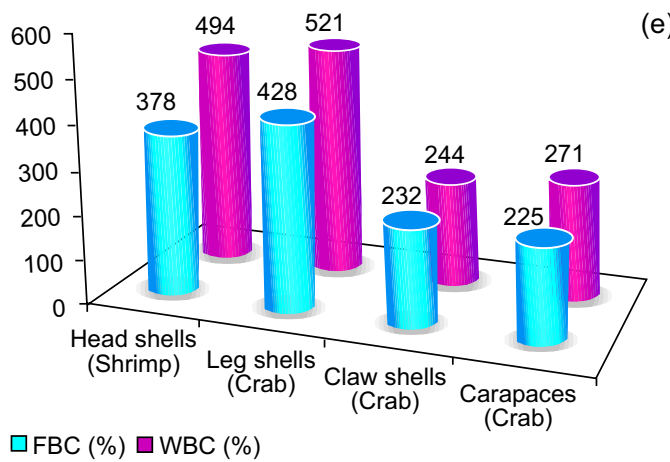

$\mathrm{N}=$ nitrogen; $\mathrm{DD}=$ degree of deacetylation; $\mathrm{FBC}=$ fat binding capacity; $\mathrm{WBC}=$ water binding capacity.

Fig. 2. Percentage yields of four isolated chitin and chitosan samples. 
$270 \%$ water binding capacities, respectively, while working on five commercial chitosans from shrimp and crab reported the range for $\mathrm{WBC}$ as $58 \%$ to $805 \%$, which satisfies the low results given by crab claw shells and crab carapace chitosan samples in Fig. 2e. For different crustaceans ranges for water binding capacity (WBC) value are claimed as 355\%-611\% (No et al., 2000); $58 \%-805 \%$ for shrimp chitosan and $491 \%-555 \%$ for crab chitosan (Kucukgulmez et al., 2011).

The values of FBC (fat binding capacity) of the chitosan samples were in the range of $378 \%$ to $428 \%$ excluding crab claw shells and crab carapace. These FBCs by Chitosan1 (shrimp head shell) and crab leg shells were found higher than those reported by No et al. (2003), but lower than findings for crawfish $(706 \%)$ and for commercial crab (587\%). The value $370 \%$ for shrimp chitosan is in good resemblance to shrimp head shell results. Crab leg shells with $428 \%$ is also in accordance with the value $(490.10 \%)$ of crab chitosan by Ocloo et al. (2011).The lower values by crab claw shells (claw) and crab carapace (carapace) chitosan samples show their less capacity to bind fat, hence low applicability. The decreased viscosity as observed may be a cause of decrease in fat binding capacities in crab claw shells and crab carapace chitosan samples.

FTIR analysis. Figure $3(\mathrm{a}, \mathrm{b}, \mathrm{c}, \mathrm{d}, \mathrm{e})$ presents the results of fourier transform infrared spectroscopy for chitosan samples isolated from shrimp head waste, crab leg shells, crab claws crab carapaces and pure chitosan, respectively. All infrared spectra are significantly similar to each other in regard of characteristic peaks region $3300-3500 \mathrm{~cm}^{-1}, 1400-1650 \mathrm{~cm}^{-1}$ and $500-600 \mathrm{~cm}^{-1}$ which is consistent to previous researchers. Some characteristic peaks of chitosan in literature are quoted as $1070 \mathrm{~cm}^{-1}$ for $\mathrm{C}-\mathrm{O}$ stretching, $1570 \mathrm{~cm}^{-1}$ for $\mathrm{N}-\mathrm{H}$ bending vibration of $1^{\circ}$ amides, $1555 \mathrm{~cm}^{-1}$ for $\mathrm{N}-\mathrm{H}$ bending vibration of amide II band, $1655 \mathrm{~cm}^{-1}$ for $-\mathrm{C}=\mathrm{O}$ stretch vibration of $2^{\circ}$ amide $\mathrm{I}$ band and 3300 $\mathrm{cm}^{-1}$ for $-\mathrm{CH}_{3},-\mathrm{CH}_{2}$ bands (Lee et al., 2005).

Intermolecular $-\mathrm{H}$ bands are mostly attributed to the broad peak at about $3300 \mathrm{~cm}^{-1}$, as reported by Kucukgulmez et al. (2011). Similarly, at $600 \mathrm{~cm}^{-1}$ out plane bending $-\mathrm{OH}$ vibrations were noted. The peaks in $1380-1442 \mathrm{~cm}^{-1}$ region represented the asymmetric and symmetric bending vibrations associated with $-\mathrm{CH}_{3}$ groups. According to the study of Li et al. (1998) the bands at $1415 \mathrm{~cm}^{-1}$ indicate the $-\mathrm{C}-\mathrm{H}$ bending vibrations of $-\mathrm{CH}_{2}$.
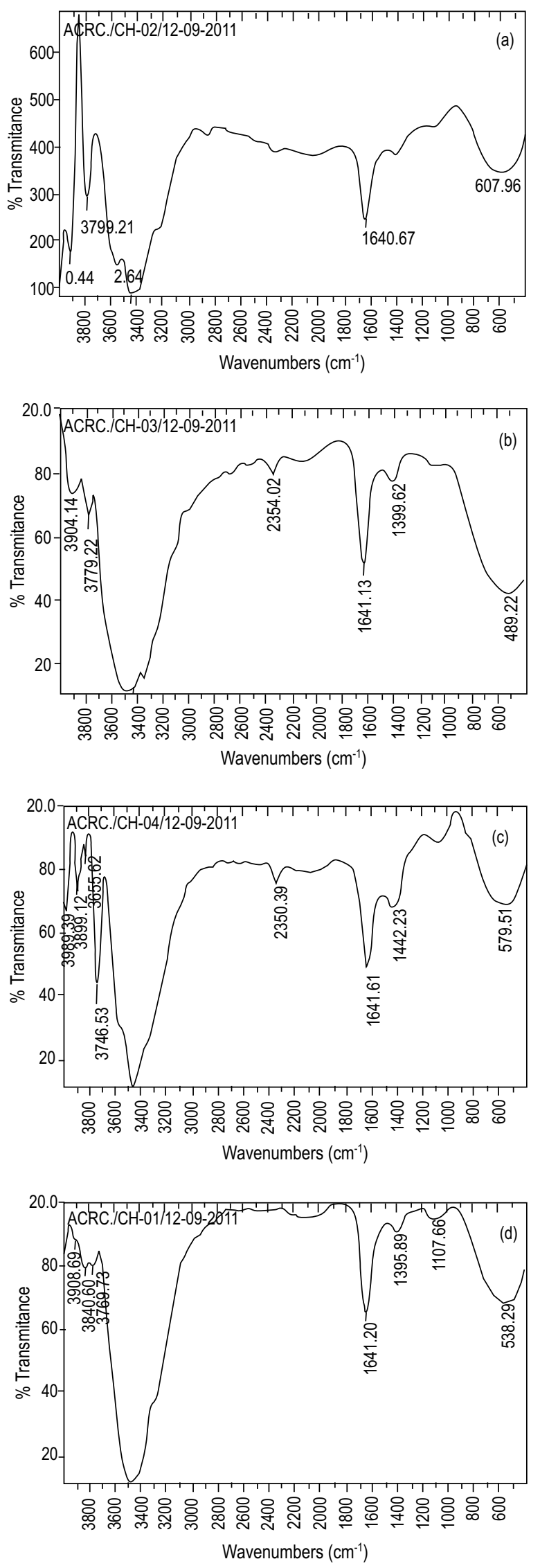


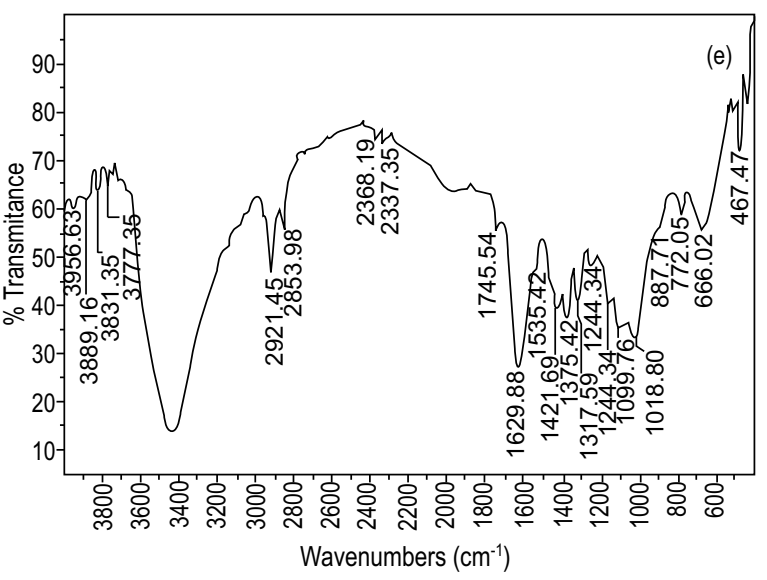

Fig. 3. FTIR spectrum of (a) isolated shrimp head shell chitosan; (b) isolated crab leg shells chitosan; (c) isolated crab claw shells chitosan; (d) isolated crab carapace chitosan; (e) pure chitosan.

\section{Conclusion}

Chitin and its derivative chitosan were isolated from waste of two local crustaceans and its various physicochemical and functional characteristics of prepared chitosan samples were investigated. In this way, the environmental pollution may be reduced by an attractive route of seafood waste management and the broad spectrum in industrial sector. On the basis of present study it was concluded that chitosan can be used as ecofriendly adsorbent.

\section{References}

Abdou, E.S., Nagy, K.S.A., Elsabee, M.Z. 2008. Extraction and characterization of chitin and chitosan from local sources. Bioresource Technology, 99: 1359-1367.

Alves, N.M., Mano, J.F. 2008. Chitosan derivatives obtained by chemical modifications for biomedical and environmental applications. International Journal of Biological Macromolecules, 43: 401-414.

AOAC, 2005. Official Methods of Analysis of AOAC International, $18^{\text {th }}$ edition, AOAC International, Gaithersburg, Maryland, USA.

Bolat, Y., Bilgin, S., Gunlu, A., Izci, L., Koca, S.B., Cetinkaya, S., Koca, H.U. 2010. Chitin-chitosan yield of freshwater crab (Potamon potamios, Olivier 1804) shell. Pakistan Veterinary Journal, 30: 227231.

Bough, W.A., Salter, W.L., Wu, A.C.M., Perkin, B.E.
1978. Influence of manufacturing variables on the characteristics and effectiveness of chitosan products. I- Chemical composition, viscosity and molecular-weight distribution of chitosan products. Biotechnology and Bioengineering, 20: 1931-1943.

Chandumpai, A., Singhpibulporn, N., Faroongsarng, D., Sornprasit, P. 2004. Preparation and physicochemical characterization of chitin and chitosan from the pens of the squid species, Loligo lessoniana and Loligo formosana. Carbohydrate Polymers, 58: 467-474.

Diaz-Visurraga, J., García, A., Cárdenas, G. 2010. Lethal effect of chitosan-Ag (I) films on Staphylococcus aureus as evaluated by electron microscopy. Journal of Applied Microbiology, 108: 633-646.

Du, W.L., Niu, S.S., Xu, Y.L., Xu, Z.R., Fan, C.L. 2009. Antibacterial activity of chitosan tripolyphosphate nanoparticles loaded with various metal ions. Carbohydrate Polymers, 75: 385-389.

Du, W.L., Xu, Z.R., Han, X.Y., Xu, Y.L., Miao, Z.Y. 2008. Preparation characterization and adsorption properties of chitosan nanoparticles for eosin Y as a model anionic dye. Journal of Hazardous Materials, 153: 152-156.

Huang, X.Y., Bin, J.B., Bu, H.T., Jiang, G.B., Zeng, M.H. 2011. Removal of anionic dye eosin Y from aqueous solution using ethylenediamine modified chitosan. Carbohydrate Polymers, 84: 1350-1356.

Iqbal, J., Tirmizi, S.A., Mirza, M.L. 2005. Adsorption status of some transition metal ions on pretreated fish scales. Journal of The Chemical Society of Pakistan, 27: 77-81.

Kasaai, M.R., Arul, J., Charlet, G. 2000. Intrinsic viscosity-molecular weight relationship for chitosan. Journal of Polymer Science Part B: Polymer Physics, 38: 2591-2598.

Khan, T.A., Peh, K.K., Chng, H.S. 2002. Reporting degree of deacetylation values of chitosan: the influence of analytical methods. Journal of Pharmacy and Pharmaceutical Sciences, 5: 205-212.

Kim, S.K., Mendis, E. 2006. Bioactive compounds from marine processing byproducts - A review. Food Research International, 39: 383-393.

Kucukgulmez, A., Celik, M., Yanar, Y., Sen, D., Polat, H., Kadak, A.E. 2011. Physicochemical characterization of chitosan extracted from Metapenaeus stebbingi shells. Food Chemistry, 126: 1144-1148.

Kurita, K. 2006. Chitin and chitosan: functional biopolymers from marine crustaceans. Marine Biotechnology (New york), 8: 203-226. 
Lee, M.Y., Hong, K.J., Kajiuchi, T., Yang, J.W. 2005. Synthesis of chitosan-based polymeric surfactants and their adsorption properties for heavy metals and fatty acid. International Journal of Biological Macromolecules, 36: 152-158.

Li, Q., Weng, S., Wu, J., Zhou, N. 1998. Comparative study on structure of solubilized water in reversed micelles. 1 FT-IR spectroscopic evidence of water/ AOT/n-heptane and water/NaDEHP/n-heptane systems. The Journal of Physical Chemistry B, 102: 3168-3174.

Martino, A.D., Sittinger, M., Risbud, M.V. 2005. Chitosan: a versatile biopolymer for orthopaedic tissue-engineering. Biomaterials, 26: 5983-5990.

Moorjani, M.N., Achutha, V., Khasim, D.I. 1975. Parameters affecting the viscosity of chitosan from prawn waste. Journal of Food Science and Technology, 12: 187-191.

No, H.K., Lee, S.H., Park, N.Y., Meyers, S.P. 2003. Comparison of physicochemical, binding and antibacterial properties of chitosans prepared without and with deproteinization process. Journal of Agricultural and Food Chemistry, 51: 7659-7663.

No, H.K., Lee, M.Y. 1995. Isolation of chitin from crab shell waste. Journal of The Korean Society of Food Science and Nutrition, 24: 105-113.

Ocloo, F.C.K., Quayson, E.T., Adu-Gyamfi, A., Quarcoo, E.A., Asare, D., Serfor-Armah, Y., Woode, B.K. 2011. Physicochemical and functional characterization of radiation-processed shrimp chitosan. Radiation Physics and Chemistry, 80: 837-841.

Parihar, M.M. 2011. Export to (EU) markets: The EU authorities have once again declined Pakistan the opportunity to export fish to their market. Dawn
Newspaper, November 27.

Synowiecki, J., Al-Khateeb, N.A. 2003. Production, properties and some new applications of chitin and its derivatives. Critical Reviews in Food Science and Nutrition, 43: 145-171.

Tajik, H., Moradi, M., Rohani, S.M.R., Erfani, A.M., Jalali, F.S.S. 2008. Preparation of chitosan from brine shrimp (Artemia urmiana) cyst shells and effect of different chemical processing sequences on the physiological and functional properties of the product. Molecules, 13: 1263-1274.

Tharanathan, R.N., Kittur, F.S. 2003. Chitin-the undisputed biomolecule of great potential. Critical Reviews in Food Science and Nutrition, 43: 61-87.

Wang, J.C., Kinsella, J.E. 1976. Functional properties of novel proteins: alfalfa leaf protein. Journal of Food Science, 41: 286-292.

Yang, J., Shih, I.I., Tzeng, Y., Wang, S. 2000. Production and purification of protease from a Bacllius subtilis that can deproteainize crustacean wastes. Enzyme and Microbial Technology, 26: 406-413.

Youn, D.K., No, H.K., Prinyawiwatkul, W. 2007. Physical characteristics of decolorized chitosan as affected by sun drying during chitosan preparation. Carbohydrate Polymers, 69: 707-712.

Zaku, S.G., Emmanuel, S.A., Aguzue, O.C., Thomas, S.A. 2011. Extraction and characterization of chitin; a functional biopolymer obtained from scales of common carp fish (Cyprinus carpio 1.): A lesser known source. African Journal of Food Science, 5: $478-483$.

Zeng, D., Wu, J., Kennedy, J.F. 2008. Application of a chitosan flocculants to water treatment. Carbohydrate Polymers, 71: 135-139. 